\title{
Patrimonio, turismo y género. Estrategias para integrar la perspectiva de género en el patrimonio histórico
}

\author{
Margarita M. Birriel Salcedo | Instituto de Estudios de las Mujeres y de Género, Universidad de Granada \\ Carmen Rísquez Cuenca | Instituto Universitario de Investigación en Arqueología Ibérica, Universidad de Jaén
}

URL de la contribución <www.iaph.es/revistaph/index.php/revistaph/article/view/3753>

Con frecuencia se define el turismo como una de las industrias de mayor crecimiento en el planeta. Este sector también tiene el dudoso honor de ser uno de los más segregados por sexo y donde con suma frecuencia se reproducen los estereotipos de género (KINKAID; HALL, 2000). En nuestro país ha adquirido, sin duda, una gran relevancia económica, tanto por el número de personas que emplea como por la riqueza que genera. El creciente interés de la sociedad por los lugares vinculados con el pasado y con la memoria ha hecho posible que estos se integren en las formas de ocio más demandadas en la actualidad, entre las que destaca el turismo cultural. En este contexto, el patrimonio histórico ha alcanzado un reconocimiento específico en el seno de la industria turística, siendo considerado además como un valioso motor de desarrollo económico y social. Esto ha generado una preocupación por preservar este patrimonio y también por su explotación.

Como resultado, se ha abierto un proceso de activación del patrimonio, con un largo recorrido que va desde la transformación de los bienes en recursos patrimoniales y turísticos, hasta su conversión en productos patrimoniales. En este camino es importante tener en cuenta el objetivo esencial de estos productos, guardianes de la memoria tangible de la sociedad, que no es obtener beneficios económicos (que también) sino conservar, investigar y acercar ese legado a la ciudadanía (RODRÍGUEZ SANTANA; SÁENZ SAGASTI, 2014: 117). En consecuencia, el turismo no puede ser considerado simplemente como un negocio o industria, sino como una poderosa arena cultural y un proceso relacional que conforma y es conformado por representaciones generizadas de lugares, gentes, naciones o culturas. Con este potencial, como ha subrayado Aitchinson, se hace urgente incluir los instrumentos de análisis feministas en el turismo, en especial con relación al patrimonio, para poder enfrentar las problemáticas derivadas de unas formas androcéntricas de representar el pasado y así afrontar el reto de crítica a los mecanismos de reproducción de la desigualdad construyendo nuevas propuestas más igualitarias y democráticas sobre el patrimonio (AITCHINSON, 2001).

El concepto de patrimonio es una construcción social en la que se sustentan una serie de valores que definen las señas de identidad colectiva y cumplen un rol fundamental en la construcción de una memoria común. Con estas palabras abríamos nuestra reflexión (en el texto que servía para enmarcar el debate de este número de la revista) ${ }^{1}$ y afirmábamos un conjunto de principios que debemos tener en cuenta. El primero hace referencia a que el patrimonio es un constructo. Es decir, no existe en sí mismo sino que es el resultado de unos procesos de selección y significación de artefactos, monumentos, lugares, valores etc. La primera palabra clave es selección ya que con mucha frecuencia, cuando se habla de patrimonio, se entiende como todo el legado o herencia del pasado, pero no todo el pasado es patrimonio. Otro aspecto relevante a considerar es lo que se ha transmitido, pues no debemos entenderlo únicamente como transmisión de bienes, sino que debe incluir también a los valores, donde el patrimonio "evoca un conjunto de valores que tienen raíz en lo 'sensible' de las identidades, la historia y las ciencias sociales" (CABELLO PADIAL, 2012: 137). De ahí que en el desarrollo de la cadena lógica básica (investigar, proteger, conservar y difundir), se reflejen aquellos bienes y valores que se han seleccionado para ser transmitidos, por lo que el resultado final no es neutro, sino producto de una elección intencionada. 
Así pues, el patrimonio es una forma de memoria, un constructo social modelado por las preocupaciones políticas, sociales o ideológicas del presente, y un futuro imaginado. En consecuencia, por mucho que importen los objetos o los lugares, lo que más importancia tiene son los significados ligados a ellos y las representaciones que, a través suyo, se crean. Ese proceso en cualquier sociedad concreta que estudiemos responde a lo que Smith (2006) Ilama el discurso patrimonial autorizado (DPA), es decir, responde preferentemente a políticas de la memoria controlada por los grupos dominantes en dicha sociedad, sean políticos, sociales, religiosos o étnicos.

EI DPA es un discurso profesional que, pese a las diferencias locales/sectoriales, comparte una serie de rasgos comunes en el que participan políticos, conservacionistas, profesionales del patrimonio o sociedades culturales. Básicamente estos subrayan la materialidad (artefactos, lugares) y el valor innato y universal del patrimonio, frecuentemente ligados a la identidad nacional y a la historia de la nación. Patrimonio preservado para legar a las generaciones futuras. Estas concepciones parten de la propia historicidad de las políticas de la memoria impulsadas desde la llustración y la construcción de los estados-nación del siglo XIX, muy ligadas a la configuración de las identidades nacionales (CAPEL SÁEZ, 2014). Pero no sólo, ya que quienes construyeron y definieron esta política respondían a valores estéticos y sociales vinculados a una clase y a un género. Fueron, principalmente, varones de las clases acomodadas e intelectuales como Víctor Hugo, quienes abanderaron, frente a la destrucción/reconstrucción masiva de las antiguas urbes europeas, la conservación de monumentos, el anclaje de los lugares de memoria con la nación, pero también quienes nos transmitieron una experiencia social y cultural que configuró las primeras ideas sobre el patrimonio. Como Lowenthal apunta: "el tejido histórico pertenece a los Grandes y Buenos; el patrimonio es la tarea pastoral de los caballeros" (1992: 159). Estamos hablando no sólo de una idea de nación y ciudadanía sino también de unos valores de clase y género que atraviesa los discursos oficiales sobre el patrimonio.

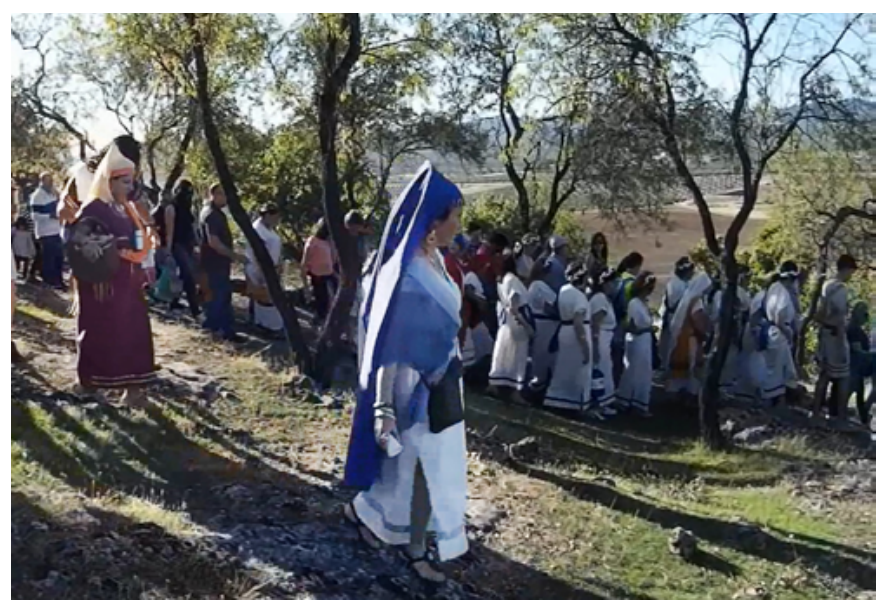

Las investigaciones sobre el santuario de la Cueva de la Lobera (Castellar, Jaén), sobre todo las últimas y su adecuación para la visita, han hecho que en el pueblo se convierta en uno de sus referentes identitarios. Visita al santuario en los días del equinoccio de otoño de 2015 en el maco de distintas actividades programadas por el ayuntamiento de Castellar | foto Proyecto GENDAR

Los lugares, las historias, los monumentos, la lengua, los ritos cívicos..., todo aquello que una sociedad reconoce como patrimonio es usado para construir narrativas de inclusión/exclusión que definen comunidades, identidades. Pero como ya se ha dicho no sólo es la nación, en tanto que comunidad imaginada, lo que se define pues también los marcadores de clase, género o raza se entrelazan en la definición de la comunidad. Sin embargo, fueron y siguen siendo construcciones sociales, específicas en el tiempo, por tanto, sus significados pueden ser cambiados, reinterpretados, readecuados a nuevos tiempos o demandas sociales. Esto puede comprobarse en los deslizamientos que ha habido en los focos de interés patrimonial en los últimos 30 años: de un patrimonio muy centrado en la arquitectura aristocrática a la promoción de centros mineros o industriales; del interés exclusivo en los héroes nacionales a la pertinencia de estudiar y conservar los procesos de trabajo y a los héroes cotidianos; o aún más claro, los cambios que han sufrido los museos europeos vinculados a la conservación de la memoria imperial que en los últimos años han transformado por completo qué cuentan y cómo. Este último ejemplo es paradigmático de cómo los cambios en la composición étnica de unos determinados países (Holanda, Inglaterra), el poder creciente de nuevos 
a debate Patrimonio, turismo y género. Estrategias para integrar la perspectiva de género en el patrimonio histórico | coordinan Margarita M. Birriel Salcedo, Carmen Rísquez Cuenca

grupos que ya no son las antiguas élites económicas o intelectuales, y donde el ciudadano ya no puede ser definido sólo como el varón, blanco, protestante, ha exigido redefinir todo lo que esos museos imperiales eran. Ya no son el despliegue épico de la superioridad occidental sino espacios donde se ponen en valor otras culturas, se explica como agresión el tráfico de esclavos o la depredación colonial. Aunque dichas reacomodaciones no están exentas de tensiones, incluso, conflictos abiertos. Aquí en España vivimos diariamente uno de esos conflictos relacionados con lo que se ha llamado la memoria histórica. El conflicto es resultado de las demandas de cambio, y las resistencias subsiguientes, del DPA de los vencedores en el despliegue de la memoria de la Guerra Civil y el franquismo.
Por tanto, hay reacomodos, cambios, pero son conflictivos, complejos en su negociación y no siempre exitosos. Por ello, y a pesar de que las mujeres han ganado cuotas importantes de poder en nuestras sociedades, contemplamos con asombro cómo los sistemas discursivos (textos e imágenes) que se nos muestran en los distintos espacios patrimoniales siguen evidenciando un pensamiento androcéntrico y patriarcal, determinante en la construcción de nuestros referentes histórico-culturales. Esto conlleva que se continúe transmitiendo a todo el público que visita estos lugares una imagen social del patrimonio histórico que ha sido sistemáticamente denunciada por el movimiento feminista o los estudios de género. Ante todo, desvela que el DPA se sustenta aún en un orden patriarcal, cuyas formas pres-

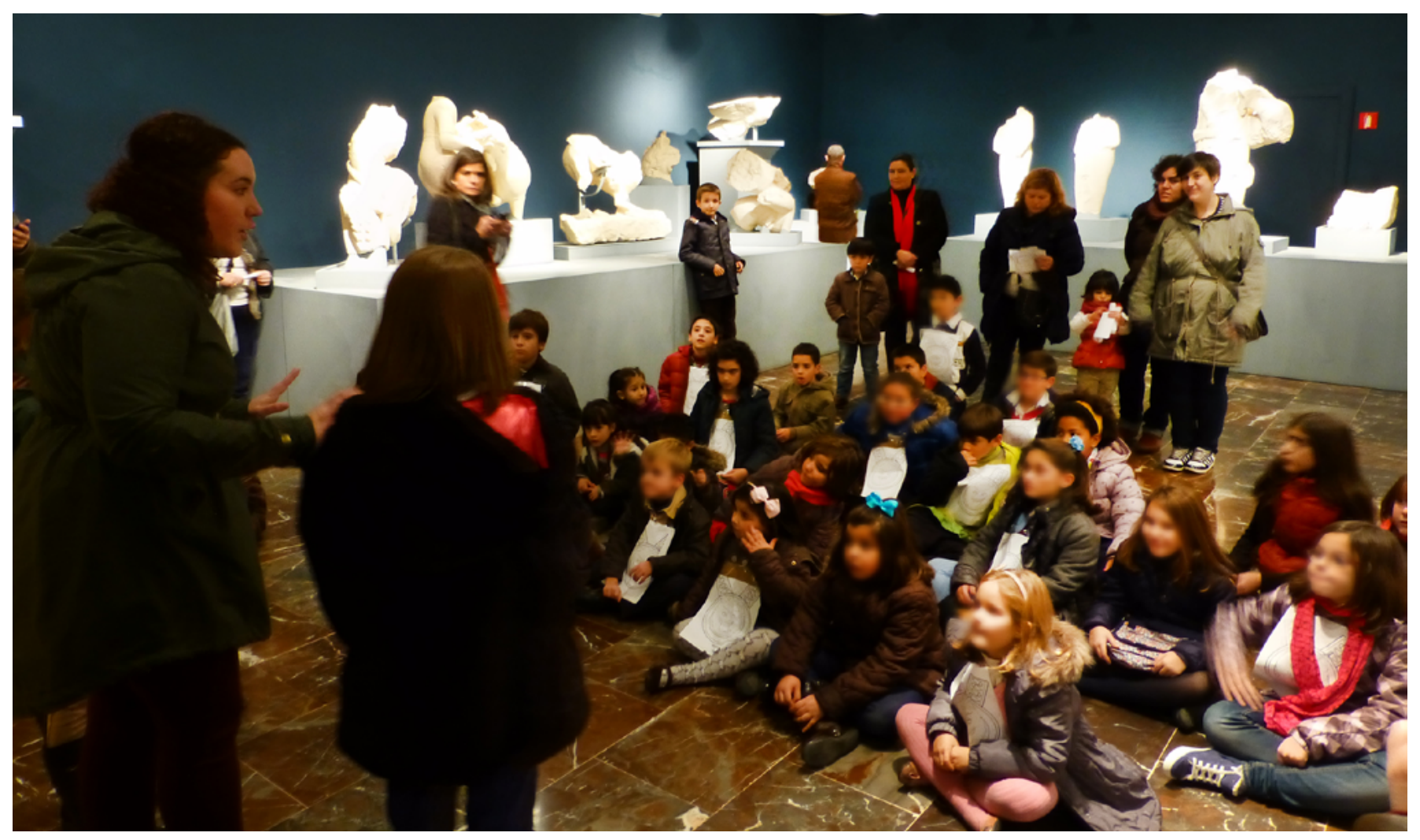

Actividad didáctica llevada a cabo en el Museo de Jaén por la empresa Musaraña Gestión de Museos, dentro del programa de dinamización Viaja en Navidad al tiempo de los íberos de la Diputación de Jaén (2013). Importancia de trasladar desde edades tempranas y a través del patrimonio no sólo el conocimiento de la Historia, sino también de valores en igualdad | foto Musaraña Gestión de Museos S. L. 
criptivas de la masculinidad y la feminidad son impuestas como las únicas posibles, y, por tanto, muestran sólo la perspectiva de quien está en el centro de la vida social (varón, blanco, occidental, poderoso) y, en consecuencia, definen qué es pertinente recordar, conservar, mostrar y transmitir al futuro (HAYDEN, 2003).

En este sentido lo primero que detectamos ( $\mathrm{y}$ resulta muy evidente) es la exclusión y la invisibilidad de las mujeres y de sus acciones en las representaciones del pasado construidas a través del patrimonio. Esto sucede de muy diversas formas que van desde la ausencia de lugares de memoria relacionados con la historia de las mujeres a la exclusión de las féminas del canon de artistas. Nosotras hemos dejado constancia, explícitamente, de los sesgos androcéntricos de esos despliegues en centros de interpretación comarcales o museos (ROBLES VIZCAÍNO; BIRRIEL SALCEDO, 2012; RÍSQUEZ CUENCA; HORNOS MATA, 2000; HORNOS MATA; RÍSQUEZ CUENCA, 2005), al igual que lo hacen las contribuciones que acompañan este texto en la sección Perspectivas de revista ph de este número. Cómo podemos leer en ellas las acciones inmediatas puestas en marcha para contrarrestar estos discursos oficiales, que pasan inicialmente por visibilizar, por hacer presentes a las mujeres en los museos, los sitios arqueológicos o en el espacio urbano. Algunos de los textos manifiestan propuestas claras en los museos, bajo la perspectiva feminista, junto a diversas iniciativas que se vienen llevando a cabo. También son evidentes algunas de las ofertas para sitios concretos centradas en el patrimonio arqueológico e histórico, o para los espacios urbanos, en los que las mujeres también carecen de esa memoria histórica. Pensemos en el callejero de muchas de nuestras ciudades. La mayoría de la población repara poco en el nombre de la calle o la plaza pero el nombre, sobre todo si es de persona, es asumido siempre como alguien importante, alguien que contribuyó a forjar la comunidad. En cualquier caso, acciones en apariencia pequeñas como colocar el foco de la atención en las pintoras o las mecenas no sólo satisface el prurito de ver a más mujeres en los libros, sino que abre la puerta a que quienes consumen o simplemente son espectadoras/es de ese patrimonio se pregunten qué otras cosas enmascaran el discurso patrimonial (BIRRIEL SALCEDO, 2005).

Esas otras cosas se refieren a la perpetuación de los estereotipos de género. Es decir, las mujeres pueden estar presentes pero la forma en que se explica o visualiza el patrimonio tiende a perpetuar los estereotipos al atribuir a mujeres o varones ocupaciones, gestualidades o valores naturalizados y eternos. Ejemplos, como siempre, hay muchos: el uso continuado de un lenguaje sexista, caso de utilizar hombre para designar al conjunto de la humanidad, lo que refuerza la idea de que la humanidad lo es más encarnada en el varón. En la misma línea se ha cuestionado el empleo sólo del cuerpo masculino para mostrar la evolución de los seres humanos, esta materialidad corpórea masculina de lo humano refuerza la idea de que la historia de la humanidad es cosa de los varones. Todo ello contribuye a perpetuar hoy las desigualdades. No son trivialidades pues, como destaca Olwig (1999), el patrimonio contribuye a reforzar política y socialmente a aquellos que reconoce, que designa como importantes, mientras que aquellos que invisibiliza o desplaza al fondo son marginalizados. Contra esto se hace imprescindible la inclusión de género en las políticas patrimoniales y culturales de los gobiernos locales, autonómicos, estatales, etc. Hace años que venimos insistiendo en ello. Sin embargo, y aunque ha habido acciones concretas que son de interés, lo cierto es que no hay unas políticas de intervención claras en este sentido y, desde luego, no están implementadas por los y las profesionales o los grupos que las han demandado.

Señala Irina Bokova, directora general de la Unesco que "en los tiempos en que los Estados se encuentran definiendo los perfiles de sus agendas de desarrollo post2015, existe un reconocimiento creciente del papel de la cultura en la promoción del desarrollo social inclusivo, donde la igualdad de género es una parte fundamental de la ecuación para un desarrollo más inclusivo y sostenible". Lo argumenta en el prólogo del informe que la UNESCO ha realizado sobre Igualdad de género: patrimonio y creatividad (2015), en el que se analiza ampliamente cómo la cultura puede ser una aliada fundamental de la igual- 
a debate Patrimonio, turismo y género. Estrategias para integrar la perspectiva de género en el patrimonio histórico | coordinan Margarita M. Birriel Salcedo, Carmen Rísquez Cuenca

dad de género, poniendo el foco de manera especial en la creatividad y en el patrimonio. A este último dedica el capítulo dos, examinando la igualdad de género y el patrimonio en relación con los sistemas de valores que gobiernan nuestro sentido de identidad y, por lo tanto, influyen en la interpretación, identificación y transmisión del patrimonio en el tiempo. Lo realmente relevante de este estudio es que intenta aportar aquellas cuestiones significativas a los debates internacionales en la agenda post-2015, proponiendo recomendaciones a los gobiernos, que son los encargados de tomar decisiones, a la comunidad internacional y a la sociedad civil. Sólo tenemos que exigir y reivindicar que se cumpla. No podemos olvidar que tenemos leyes relacionadas con la igualdad de mujeres y hombres -tanto a nivel estatal como autonómico- por lo que se trata de la obligatoriedad de cumplirlas.

Pero también el género debe estar en la agenda de aquellas y aquellos que desde el aula, el museo, la exposición o el yacimiento arqueológico definen lugares, cosas o experiencias como patrimonio. Algunos de los escritos aportados en el debate de esta sección se centran precisamente en la didáctica del patrimonio desde la perspectiva de género y en los procesos de enseñanza y aprendizaje de la historia.

Una reflexión igualmente importante merece la aparición y el auge que están adquiriendo las nuevas tecnologías de la Información y las Comunicaciones (TIC), como herramientas que, aplicadas tanto a la interpretación y difusión del patrimonio como a su incorporación en los procesos educativos, buscan ayudar en su comprensión. También aquí cabe fijarnos en los objetivos que se han seleccionado, qué contenidos se transmiten y cómo se han definido las narraciones e imágenes que se van a mostrar. Se están poniendo en marcha toda una serie de estrategias que inciden, más si cabe, en el relato audiovisual donde se fabrica un punto de vista determinado eligiendo los temas, las historias, las cosas o personas que van a ser narradas o ignoradas $\mathrm{y}$, como sostiene Pilar Aguilar, aunque ella lo hace con relación al cine, éstos "tienen una enorme capacidad para educar emociones, mapas afectivos, sentimientos e imaginarios, nos fabrican recuerdos, nos proponen modelos, nos enseña códigos de conducta" (2015: 25-27). Hay que aprovechar estas herramientas para crear nuevos relatos que incorporen los resultados obtenidos a partir de las investigaciones feministas y de género, las cuales aportan nuevos enfoques a la lectura del patrimonio, distintos a los que tradicionalmente se han venido efectuando. Las TIC pueden servirnos, en este caso, como vehículo para trasladar estos discursos, inclusivos y equitativos, a los espacios turísticos.

En definitiva, se hace necesario introducir en estos espacios de la memoria la perspectiva de género como una herramienta crítica, analítica y reflexiva. El hecho es que estos espacios no sólo poseen una alta capacidad de incidir en la construcción y formación de identidades, subjetividades, imaginarios y memorias colectivas inclusivas, sino también de crear otras formas de aprendizaje desde la igualdad. Esta perspectiva dará entrada, por una parte, a las mujeres del pasado al hacerlas visibles, valorando así el legado que nos dejaron y haciendo más compleja nuestra mirada y, por otra, a las mujeres de hoy y de mañana, estableciendo pasarelas sumamente enriquecedoras entre el pasado, el presente y el futuro. Por todo ello, se impone abrir paso a un nuevo modelo que promueva la igualdad de género desde el patrimonio histórico.

Las distintas aportaciones que se recogen en este número de Perspectivas evidencian, desde áreas muy diversas, esta necesidad y nos muestran una tarea en la que tenemos que insistir, trabajando de manera colectiva, para salvar las dificultades que seguimos encontrando en el camino, pues como dice Almudena Hernando "sólo pudiendo dar la mano a quien ya se ha enfrentado a ellas, o a quien se enfrenta simultáneamente con nosotros, se puede vislumbrar que el camino sigue, que no lo interrumpe un precipicio, que sólo se trata de salvar otra más de sus dificultades" (2015: 17). Desde aquí nuestro agradecimiento a quienes habéis participado y enriquecido con vuestras experiencias y reflexiones este debate, que sólo acaba de abrirse y en el que tenemos una larga senda que recorrer. 


\section{BIBLIOGRAFÍA}

- AA.VV. (2012) Conocimiento y percepción del patrimonio histórico en la sociedad española. Madrid: Fundación Caja Madrid, 2012

- AGUILAR CARRASCO, P. (2015) La ficción audiovisual como instrumento de educación sentimental en la modernidad. En HERNANDO GONZALO, A. (ed.) Mujeres, hombres, poder. Subjetividades en conflicto. Madrid: Traficantes de sueños, 2015, pp. 25-53

- AITCHISON, C (2001) Theorizing Other discourses in tourism, gender and culture. Can the subaltern speak (in tourism)? Tourist Studies, vol. 1 (2), 2001, pp. 133-147

- BIRRIEL SALCEDO, M. M. (2005) A propósito de Clío: miradas feministas. En TORRES RAMÍREZ, I. (coord.) Miradas desde la perspectiva de género. Estudios de las Mujeres. Madrid: Narcea, 2005, pp. 63-75

- CABELlO PADIAL, G. (2012) Patrimonio, transmisión y derivas de la memoria. En GONZÁLEZ ALCANTUD, J. A.; CALATRAVA ESCOBAR, J. (ed.) Memoria y Patrimonio. Concepto y reflexión desde el Mediterráneo. Granada: Universidad, 2012, pp. 125-148

- CAPEL SÁEZ, H. (2014) El patrimonio: la construcción del pasado y del futuro. Barcelona: Ediciones El Serbal, 2014

- HAYDEN, D. (2003) The Power of Place Project: Claiming Women's History in the Urban Landscape. En DUBROW, G: GOODMAN, J. (ed.) Restoring Women's History Through Historic Preservation. Baltimore: The Johns Hopkins University Press, 2003, pp. 199-213

- HERNANDO GoNZALO, A. (ed.) (2015) Mujeres, hombres, poder. Subjetividades en conflicto. Madrid: Traficantes de sueños, 2015

- HORNOS MATA, F.; RÍSQUEZ CUENCA, C. (2005) Representación en la actualidad: las mujeres en los museos. En SÁNCHEZ ROMERO, M. (coord.) Arqueología y género. Monografías de Arte y Arqueología, n. ${ }^{\circ}$ 64, 2005, pp. 479-490

- KINKAID, V; HALL, D. (2000) Theorizing Gender in Tourism Research. Tourism Recreation Research, vol 25 (1), 2000, pp. 71-84

- LOWENTHAL, D. (1992) A Global perspective on American Heritage. En LEE, A (ed.) Past Meets Future: Saving America's Historic Enviroment. Washington: The Preservation Press, 1992, pp. $157-66$

- OLWIG, K. F. (1999) The Burden of Heritage: Claiming a Place for a West Indian Culture. American Ethnologist, vol. 26(2), 1999, pp. 370-88
- Rísquez CUENCA, C.; HORNOS MATA, F. (2000) Paseando por un museo y buscando el lugar de la mujer. Arqueología Espacial, 22, 2000, pp. 175-186

- ROBLES VIZCAÍNO, M. S.; BIRRIEL SALCEDO, M. M. (ed.) (2012) Las mujeres en la historia. Itinerarios por la provincia de Granada. Granada: EUG, 2012

- RODRÍGUEZ SANTANA, C. G.; SÁENZ SAGASTI, J. I. (2014) El liderazgo cultural en la gestión turística del Museo y Parque Arqueológico Cueva Pintada (Galdar, Gran Canaria). En VIVES-FERRÁNDIZ SÁNCHEZ, J.; FERRER GARCÍA, C. (ed.) El pasado en su lugar. Patrimonio Arqueológico Desarrollo y Turismo. III Jornadas de Debate del Museu de Prehistòria de València. Valencia: Museu de Prehistoria de Valencia, 2014, pp. 115-138

- RUIZ TORRES, P. (2007) Los discursos de la memoria histórica en España. Hispania Nova [en línea], vol. 7, 2007, pp. 305-334 <http://hispanianova.rediris.es/7/ HISPANIANOVA-2007.pdf> [Consulta: 01/02/2016]

- SMITH, L. (2006) Uses of Heritage. London: Routledge, 2006

- SOlER MONTIEL, M.; GUERRERO QUINTERO, C. (coord.) (2010) Patrimonio cultural en la nueva ruralidad andaluza. Sevilla: Instituto Andaluz del Patrimonio Histórico, 2010 (PH Cuadernos; 26)

- TREMLETT, G. (2006) Ghosts of Spain: Travels Through a Country's Hidden Past. London: Faber \& Faber, 2006

\section{NOTA}

1. Este artículo se realiza en el marco de la investigación que forma parte del proyecto HAR2013-48901-C6-6-R, financiado por el Ministerio de Economía y Competitividad, y el proyecto Recursos para la investigación de la arqueología de las mujeres y del género en España (GENDAR) HUM 1904, Proyecto de Excelencia de la Junta de Andalucía (convocatoria 2012). 